\title{
Ideal Body Shape in Young Japanese Women and Assessment of Excessive Leanness Based on Allometry
}

\author{
Yuji Takasaki ${ }^{1)}$, Tokiko Fukuda ${ }^{1)}$, Yumi Watanabe ${ }^{2)}$, \\ Tomoko Kurosawa $^{3)}$ and Keizo Shigekawa ${ }^{4}$ \\ 1) Akita University \\ 2) Takasaki University of Health and Welfare \\ 3) Seirei Women's Junior College \\ 4) Japan Red Cross Akita Junior College
}

\begin{abstract}
The present study is aimed to clarify the degree of leanness desired by contemporary young Japanese women using questionnaires and to use allometry to define the body weight boundary between the excessively lean and the others for a given height. Questionnaires on ideal body shape were distributed to female college students living in Akita and the suburbs of Tokyo. Data for 578 respondents, aged 18 to 21 years-old, were analyzed. The questionnaire asked the subjects to report their current and ideal body shape and to make a qualitative self-assessment of their weight. On average, the perceived ideal weight was $5.2 \mathrm{~kg}$ lower than the current weight. The results also revealed that young women have a tendency to misunderstand their body shape and to regard themselves as heavier than they really were. Meanwhile, we defined leanness as a state of insufficient lean body mass (LBM, $\mathrm{kg}$ ) in relation to height $(\mathrm{Ht}, \mathrm{cm})$. Allometric equation of LBM on Ht and the standard error of estimate (SEE) were calculated as $\mathrm{LBM}=3.87 \times 10^{-3} \times \mathrm{Ht}^{1.826}$ and 1.09 , respectively. The LBM boundary between the excessively lean and the others was determined using these values according to a statistical procedure comparing normal and abnormal values. The corresponding total body weight was estimated from the boundary LBM in the literature. Subsequently the body weight boundary for each height was tabulated in order to make young women reconsider weight control. The subjects were asked to assess the body weight boundary for their own height. The boundary values were found to be consistent with the sense of the subjects. J Physiol Anthropol 22 (2): 105-110, 2003 http://www.jstage.jst.go.jp/en/
\end{abstract}

Keywords: ideal body weight, young women, allometry, criteria of leanness, boundary weight

\section{Introduction}

A desire for leanness has been increasing among young women (Lee, 1993; Lake et al., 2000) who have been interested in methods for weight reduction such as dieting. Under the condition of excessive diet especially in young women around twenty years old, it is feared that they may suffer from hypotension, irregular menstruation, anorexia nervosa or even osteoporosis in the future. Therefore, selfcontrol is needed in order to avoid excessive weight reduction. Also, it is necessary to develop some methods of evaluation of leanness that reveal acceptable minimum body weight for young women. Information about minimum weight may lead young women to stop excessive dieting and develop healthy eating habits.

While the evaluation of obesity has been discussed often in studies, there are few biological investigations on the criteria of leanness. The evaluation of leanness has been investigated temporarily. For example, the Japanese Ministry of Health and Welfare (1986) published tables and figures for judging obesity and leanness, in which body weight less than 10 percentile by sex, age and height was regarded as excessive leanness. The report of the school health statistics survey by the Japanese Ministry of Education $(1983,1999)$ has been using values less than $80 \%$ of mean body weight by sex, age and height as the criteria for leanness. Recently the Japanese Society of Obesity (2000) proposed a definition of leanness as a body mass index (BMI) of less than 18.5. Similarly some investigators described the criteria of leanness (Roche et al., 1996; Malina \& Bouchard, 1991; Fox, 1979), but they only showed the values based on body build indices, percentiles of body weight or skinfold thickness from the practical point of view.

Leanness should rather be defined biologically and also theoretically. Accordingly, we defined excessive leanness as a state of insufficient lean body mass (LBM) in relation to height 
that stands for body size, and proposed the criteria of excessive leanness by means of a statistically determined boundary weight under a biologically growing system. In this context, we employed allometry, which shows the relationship between one body part and another part or the whole body, in order to assess leanness.

Thus, first the extent of leanness desired by young Japanese women was investigated using anonymous questionnaires in the present study. Secondly according to our definition of leanness, an evaluation method to distinguish lean young women from others was proposed using an allometric and statistical method.

\section{Methods}

Questionnaires on desired physique were distributed to 710 female college students living in Akita and the suburbs of Tokyo. Out of these respondents, data for 578 students aged 18 to 21 years-old were analyzed because of relatively sufficient numbers of subjects. The age breakdown was 116 aged 18 years, 227 aged 19 years, 142 aged 20 years, and 93 aged 21 years. The questionnaire asked respondents to report their current and ideal height and weight, and to assess their current body shape anonymously. Questions included items regarding: age, current height and weight, perceived ideal weight for current height, perceived ideal height and weight, body image, and the viewpoint to assess body shape. Data were analyzed descriptively with means and standard deviations, and cross tabulations.

In addition, the questionnaire asked respondents to evaluate a table of the body weight boundary for excessive leanness proposed in the present study. This table was made using allometry, which is known as an empirical theory of a biologically growing system. Since an exponential function is fitted to the relationship between two growing systems as $y=b x^{a}$, the allometric equation of lean body mass on height is calculated as $\mathrm{LBM}=\mathrm{bHt}^{\mathrm{a}}$, where $\mathrm{LBM}$ is lean body mass in $\mathrm{kg}$ and $\mathrm{Ht}$ is height in $\mathrm{cm}$. A double logarithmic function can be applied to the allometric equation and the constants "a" and "b" are determined by the least square method. As is often the case with statistical tests, a boundary line to separate unusual values from usual ones is commonly $5 \%$ for both ends of the frequency distribution, that is, $2.5 \%$ for each end. The criteria of leanness were determined according to this way. Assuming that individual lean body mass normally distributes around the line of an allometric equation in the direction of the ordinate, $2.5 \%$ of the total frequency theoretically distributes below the values at the interval of the double standard error of estimate (2SEE) downward from the line. These values were regarded as LBM boundary between the excessively lean and the others.

Using data of 1636 female high school seniors who were 15 to 17 years-old and different from the subjects for the questionnaire survey, the allometric equation of LBM on height and the standard error of estimate were calculated. LBM was estimated from height, weight and skinfold thicknesses at triceps and subscapular sites using the equations of Nagamine (1975) for body density and Brozek et al. (1963) for percent body fat.

Since it is said that essential fat is approximately $9 \%$ of body weight for young women (Lohman 1981), total body weight corresponding to boundary LBM was calculated by dividing the boundary LBM by 0.91 , and the quotient of the calculation was regarded as the boundary body weight between the excessively lean and the others. The values are tabulated in the form of a chart consisting of the boundary body weight for each height.

\section{Results}

Table 1 shows current body shape as reported by the subjects in the questionnaire survey. Current height and weight were almost the same for females between the ages of 18 and 21 years. Table 2 shows perceived ideal weight, height, and the differences between ideal and current body shape of the subjects. Ideal weight for current height was less than current weight by $5.2 \mathrm{~kg}$ on average. Ideal height was somewhat higher than current height, but ideal weight for ideal height was almost the same as that for current height. Table 3 summarizes study results by some investigators.

The responses to the question "What do you think of your current weight?" are shown in Table 4. The choices of the selfassessment were divided into five groups: thin, a little thin, normal, a little fat, and fat. Current body shape for each group was presented in this table. Nearly seventy percent of the subjects classified their own current weight into a little fat or

Table 1 Physical characteristics of respondents

\begin{tabular}{|c|c|c|c|c|c|c|c|}
\hline \multirow{2}{*}{$\begin{array}{l}\text { Age } \\
\text { group }\end{array}$} & \multirow{2}{*}{$\mathrm{n}$} & \multicolumn{2}{|c|}{ Height $(\mathrm{cm})$} & \multicolumn{2}{|c|}{ Weight (kg) } & \multicolumn{2}{|c|}{ BMI $\left(\mathrm{kg} / \mathrm{m}^{2}\right)$} \\
\hline & & Mean & SD & Mean & SD & Mean & SD \\
\hline 18 & 116 & 158.5 & 5.3 & 51.1 & 6.7 & 20.3 & 2.4 \\
\hline 19 & 227 & 158.1 & 4.7 & 51.8 & 9.5 & 20.7 & 3.6 \\
\hline 20 & 142 & 158.5 & 5.5 & 51.7 & 7.5 & 20.5 & 2.4 \\
\hline 21 & 93 & 159.7 & 5.1 & 51.5 & 6.5 & 20.2 & 2.2 \\
\hline All & 578 & 158.5 & 5.1 & 51.6 & 8.1 & 20.5 & 2.9 \\
\hline
\end{tabular}

Table 2 Differences between perceived ideal and current body shape

\begin{tabular}{ccccc}
\hline $\mathrm{n}=573$ & Mean & $\mathrm{SD}$ & \multicolumn{2}{c}{$\begin{array}{c}\text { Difference from } \\
\text { the current value }\end{array}$} \\
\cline { 4 - 5 } & & & Mean & $\mathrm{SD}$ \\
\hline $\begin{array}{c}\text { Ideal weight }(\mathrm{kg}) \\
\text { for current height }\end{array}$ & 46.3 & 4.3 & -5.2 & 4.5 \\
BMI $\left(\mathrm{kg} / \mathrm{m}^{2}\right)$ & 18.4 & 1.3 & -2.0 & 1.8 \\
\hline $\begin{array}{c}\text { Ideal height }(\mathrm{cm}) \\
\text { Ideal weight }(\mathrm{kg}) \\
\text { for ideal height }\end{array}$ & 161.1 & 4.0 & 2.5 & 5.1 \\
BMI $\left(\mathrm{kg} / \mathrm{m}^{2}\right)$ & 46.7 & 3.8 & -4.7 & 5.7 \\
\hline
\end{tabular}


Table 3 Comparison of perceived ideal body shape among various studies

\begin{tabular}{|c|c|c|c|c|c|}
\hline $\begin{array}{r}\text { Investigator } \\
\text { Year of survey } \\
\text { Subjects }\end{array}$ & $\begin{array}{c}\text { Mizuno et al. } \\
\text { 1963, } 65 \\
\text { Students }\end{array}$ & $\begin{array}{c}\text { Aoyama } \\
1976 \\
18-20 \mathrm{yr} \\
\mathrm{n}=1050\end{array}$ & $\begin{array}{l}\text { Matsuura et al. } \\
\quad 1985 \\
\text { Mean }=18.6 \mathrm{yr} \\
\mathrm{n}=433\end{array}$ & $\begin{array}{c}\text { Kojima et al. } \\
1992 \\
\text { Mean }=18.8 \mathrm{yr} \\
\mathrm{n}=468\end{array}$ & $\begin{array}{c}\text { Present study } \\
2001 \\
18-21 \mathrm{yr} \\
\mathrm{n}=578\end{array}$ \\
\hline Actual height (cm) & 156.1 & 157.9 & 157.7 & 157.7 & 158.5 \\
\hline Actual weight (kg) & 51.2 & 50.3 & 51.0 & 50.0 & 51.6 \\
\hline Actual BMI $\left(\mathrm{kg} / \mathrm{m}^{2}\right)$ & 21 & 20.2 & 20.5 & 20.1 & 20.5 \\
\hline Ideal weight $(\mathrm{kg})$ for actual height & $52.3^{\#}$ & 47.7 & 47.0 & 46.5 & 46.3 \\
\hline $\begin{array}{l}\text { Ideal BMI }\left(\mathrm{kg} / \mathrm{m}^{2}\right) \text { calculated from } \\
\text { actual height and ideal weight }\end{array}$ & $21.5^{\# \#}$ & 19.1 & 18.9 & 18.7 & 18.4 \\
\hline
\end{tabular}

${ }^{\#}$ Ideal weight for ideal height. ${ }^{\# \#}$ Ideal BMI calculated from ideal height and ideal weight.

Mean values of body shape are presented.

Table 4 Body shape in each group of self-assessed body image

\begin{tabular}{|c|c|c|c|c|c|c|c|c|c|c|}
\hline \multirow{3}{*}{$\mathrm{n}(\%)$} & \multicolumn{10}{|c|}{ Responses to the question "What do you think of your current weight?" } \\
\hline & \multicolumn{2}{|c|}{$\begin{array}{c}\text { Thin } \\
12(2.1)\end{array}$} & \multicolumn{2}{|c|}{$\begin{array}{c}\text { A little thin } \\
22(3.9)\end{array}$} & \multicolumn{2}{|c|}{$\begin{array}{c}\text { Normal } \\
138(24.2)\end{array}$} & \multicolumn{2}{|c|}{$\begin{array}{l}\text { A little fat } \\
207(36.3)\end{array}$} & \multicolumn{2}{|c|}{$\begin{array}{c}\text { Fat } \\
191(33.5)\end{array}$} \\
\hline & Mean & SD & Mean & SD & Mean & SD & Mean & SD & Mean & SD \\
\hline Current height $(\mathrm{cm})$ & 156.4 & 5.3 & 158.2 & 4.4 & 159.3 & 5.1 & 158.0 & 5.3 & 158.8 & 4.9 \\
\hline Current weight $(\mathrm{kg})$ & 40.9 & 4.2 & 44.1 & 3.6 & 47.6 & 4.5 & 50.9 & 4.4 & 56.3 & 8.0 \\
\hline Current BMI $\left(\mathrm{kg} / \mathrm{m}^{2}\right)$ & 16.7 & 1.2 & 17.6 & 0.8 & 18.7 & 1.3 & 20.4 & 1.2 & 22.3 & 2.7 \\
\hline
\end{tabular}

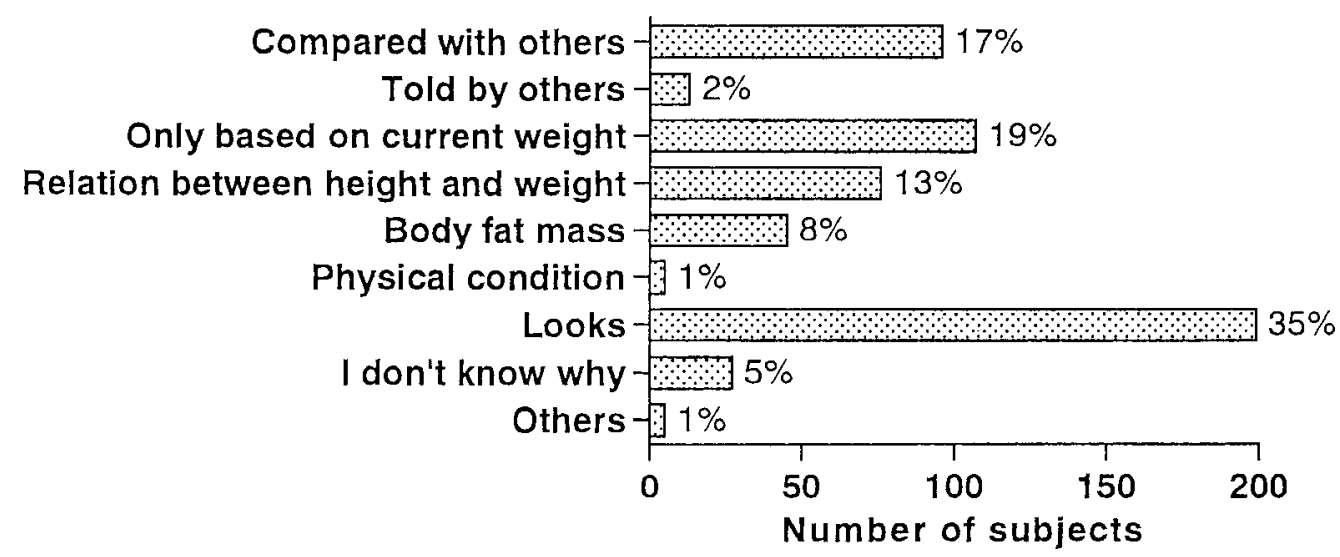

Fig. 1 Responses to the question "What is the viewpoint from which you assess your fatness or thinness?"

fat group. However, the means of current BMI for both groups were within a normal category by the criteria suggested by the Japanese Society of Obesity.

The responses to the question "What is the viewpoint from which you assess your fatness or leanness?" are illustrated in Fig. 1. Frequencies and the percentages of respondents for nine categories were indicated. This figure shows that $13 \%$ of the subjects evaluate their body shape based on the relation between height and weight, but $35 \%$ of the subjects assessed themselves from the viewpoint of looks.

From the data of 1636 female students, an allometric equation of LBM $(\mathrm{kg})$ on $\mathrm{Ht}(\mathrm{cm})$ was calculated and shown in Fig. 2. The equation was expressed as $L B M=3.87 \times 10^{-3} \times$ $\mathrm{Ht}^{1.826}(\mathrm{r}=0.528, \mathrm{P}<0.01)$. Standard error of estimate (SEE) was 1.09. Values at the interval of 2SEE below this equation indicate the boundary LBM between the excessively lean and the others. The boundary LBM was then converted to total body weight by the method described above by adding essential fat. Namely, total body weight corresponding to the boundary LBM was calculated by dividing the boundary LBM by 0.91 . The boundary body weight for each height was tabulated in the form of a chart (Table 5). 


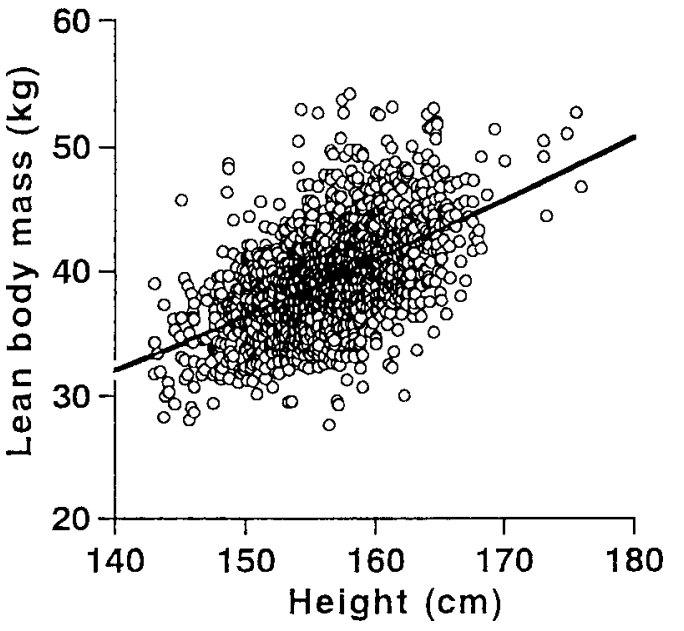

Fig. 2 Allometric line of lean body mass on height in 1636 young women. The regression equation was calculated as $\mathrm{LBM}=3.87 \times$ $10^{-3} \times \mathrm{Ht}^{1.826}(\mathrm{r}=0.528, \mathrm{P}<0.01)$

Table 5 Boundary body weight of excessive leanness for each height in young Japanese women

\begin{tabular}{cc|cc}
\hline $\begin{array}{c}\text { Height } \\
(\mathrm{cm})\end{array}$ & $\begin{array}{c}\text { Boundary weight } \\
(\mathrm{kg})\end{array}$ & $\begin{array}{c}\text { Height } \\
(\mathrm{cm})\end{array}$ & $\begin{array}{c}\text { Boundary weight } \\
(\mathrm{kg})\end{array}$ \\
\hline 140 & 32.9 & 160 & 42.6 \\
141 & 33.3 & 161 & 43.1 \\
142 & 33.8 & 162 & 43.7 \\
143 & 34.3 & 163 & 44.2 \\
144 & 34.7 & 164 & 44.7 \\
145 & 35.2 & 165 & 45.2 \\
146 & 35.7 & 166 & 45.8 \\
147 & 36.2 & 167 & 46.3 \\
148 & 36.6 & 168 & 46.8 \\
149 & 37.1 & 169 & 47.4 \\
150 & 37.6 & 170 & 47.9 \\
151 & 38.1 & 171 & 48.4 \\
152 & 38.6 & 172 & 49.0 \\
153 & 39.1 & 173 & 49.5 \\
154 & 39.6 & 174 & 50.1 \\
155 & 40.1 & 175 & 50.6 \\
156 & 40.6 & 176 & 51.2 \\
157 & 41.1 & 177 & 51.7 \\
158 & 41.6 & 178 & 52.3 \\
159 & 42.1 & 179 & 52.9 \\
\hline
\end{tabular}

Female students were asked to assess the values proposed in Table 5 and the responses to the question "What do you think of the boundary weight in our study?" are shown in Fig. 3. Forty percent of the students replied that the values of the boundary weight proposed in the present study were consistent with their feelings. Meanwhile, almost the same percentage of the students replied that the values of boundary weight were lighter or heavier than expected. The relationship between the self-estimated boundary weight of excessive leanness and the current height was investigated for the subjects as shown in Fig. 4. The regression equation of self-estimated boundary weight on the current height was expressed as $y=$

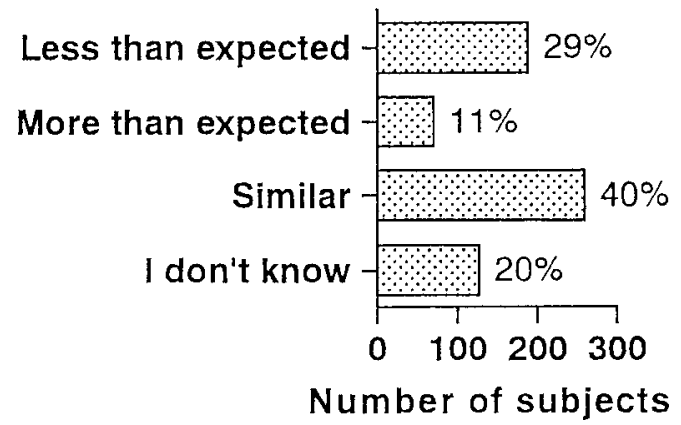

Fig. 3 Responses to the question "What do you think of the boundary weight in our study?"

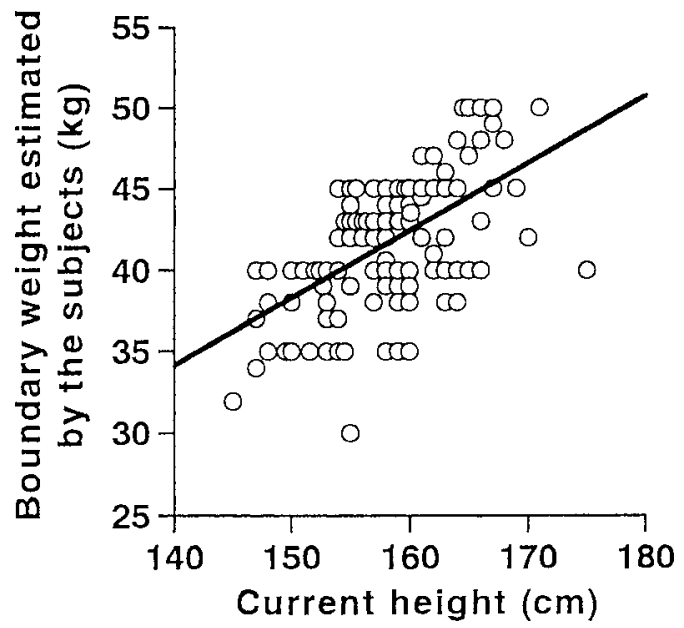

Fig. 4 The relationship between boundary weight of excessive leanness estimated by the subjects and their current height. The regression equation was calculated as $\mathrm{y}=-23.8+0.414 \mathrm{x}(\mathrm{r}=0.585, \mathrm{P}<0.01)$.

$-23.8+0.414 \mathrm{x}(\mathrm{r}=0.585, \mathrm{P}<0.01)$. There was not a great difference between boundary weight values calculated from this regression and our results.

\section{Discussion}

Mean height and weight of the subjects in the questionnaire survey were similar with the results of the recent National Nutrition Survey in 1999, which showed that mean height and weight for young women between the ages of 18 and 21 were approximately $158.1 \mathrm{~cm}$ and $51.4 \mathrm{~kg}$. Therefore, it was likely that the subjects in the present study were representative of contemporary young Japanese women.

As for perceived ideal body shape, some investigators have carried out similar surveys in the past. Table 3 shows the comparison of perceived ideal body shape among various investigations. Aoyama (1978) questioned female students on ideal body shape and his results indicated a lighter ideal body weight by $2.6 \mathrm{~kg}$ than actual body weight. Matsuura et al. (1991) assessed body shape preferences for female college students and revealed that ideal weight was less than actual weight by $4.0 \mathrm{~kg}$. Kojima et al. (1994) found ideal weight for 
female junior college students to be less than actual weight by $3.5 \mathrm{~kg}$. Compared to these investigations, the present study showed that young Japanese women wish to lose more weight. On the contrary, in the survey of Mizuno et al. (1968) who measured senior high school and college students in 1963 and 65 , the mean values of actual and ideal body weight for girls were found to be $51.2 \mathrm{~kg}$ and $52.3 \mathrm{~kg}$, respectively. These results suggest that body shape preference for young women may have changed around 1970. Young Japanese women seemed to begin to prefer slenderness around that time. In line with this, BMI during the past several decades decreased according to the data of the Ministry of Education (2000). Prior to the early 1980's, almost no reports of eating disorders in non-Caucasians existed, although the desire for slenderness and existence of eating disorders of young women had already been reported in the western countries (Caradas et al., 2001).

As for the reasons of slender body shape preference, effects of social pressures have been well documented. For instance, Ritchie (1988) introduced literature for the social pressures concerning environmental, occupational, developmental, personality and genetic factors, which may predispose women to eating disorders. Lake et al. (2000) investigated the effect of western culture on eating attitudes and the perception of body shape and supported existing literature that attitudes toward eating and perceptions of one's own body shape are influenced by cultural factors. The sociocultural effects seem to be complicated and vague, but it is possible that a high-growth period of the Japanese economy in the 1960's and early 1970's had been relevant to the change in the value of body shape preference.

According to the response to the question "What do you think of your current weight?", subjects had a tendency to misperceive their body shape (Table 4). They were apt to overestimate their body weight. In the same way, some researchers reported that young females in the western countries tend to misperceive themselves as overweight (Matsuura et al., 1991). The most frequent response to the question "What is the viewpoint from which you assess your fatness or leanness?" was "looks," which was, if anything, sensuous and groundless. These results mean that the subjects thought of their body shape with the heart rather than the head. Tiggemann and Pickering (1996) pointed out an important role of mass media in women's body dissatisfaction and drive for thinness. They said that media promote impossible standards of body shape by presenting women of ideal body image being extremely thin. In Japan, some investigators also assumed that the slender body shape preference might be partly attributable to a tendency to praise thinness as beauty in the society (Fukunaga \& Kobayashi, 1993; Imai et al., 1994; Kojima et al., 1994). Meanwhile, it was said that the perceived body shape preferences of opposite sex were regarded as the standards for young women in judging their body shapes (Fallon \& Rozin, 1985; Cohn et al., 1987). The female samples in those investigations desired to be thinner than the figures they considered most attractive to boys. While it was said that mass media leads women to weight reduction, a desire of leanness seemed to be related to awareness of the opposite sex. If this is true, a desire of leanness is instinctive and deeply rooted. According to the results of the National Nutrition Survey in 1999, the annual survey in Japan, BMIs calculated from the mean values of height and body weight for women were lower until the age of eligibility for marriage. Thereafter, BMIs rose. This phenomenon also implies that the awareness of the opposite sex is considerably related to the desire for leanness.

As mentioned at the beginning, it is necessary to propose the acceptable minimum body weight for young women. The knowledge of the minimum weight may lead young women to stop excessive weight reduction. In other words, it is likely that the presentation of a boundary body weight between the excessively lean and the other groups may make young women reconsider their weight control.

We showed the table of the boundary body weight between the excessively lean and the others. At that time, we assumed that essential fat is about $9 \%$ of body weight for young women according to a review by Lohman (1981), and calculated back to the total body weight from the boundary LBM. Essential fat is contained at the site of bone marrow, central nervous systems, mammary glands and other organs. Some investigators estimated essential fat to be higher than $9 \%$, but we adopted the minimum percentage in this study from the viewpoint of excessive leanness. When BMIs for each height were calculated from Table 5, the values were 16.7 for $150 \mathrm{~cm}$, 16.6 for $160 \mathrm{~cm}$, and 16.6 for $170 \mathrm{~cm}$. At the mean height of the subjects in this study, the lack of body weight for the excessive leanness corresponded to approximately $20 \%$ of the mean weight. This percentage agreed with one of the diagnostic criteria for anorexia nervosa, where the lack of body weight is regarded as $20 \%$ or more than standard weight.

There were a considerable number of subjects who thought the values in Table 5 were unexpected. Nevertheless the regression equation of their expected boundary weight on actual height indicated no great difference between their senses and our results. That is, as shown in Fig. 4, the values of boundary weight for each height calculated from the regression equation were $38.3 \mathrm{~kg}$ for $150 \mathrm{~cm}, 42.4 \mathrm{~kg}$ for $160 \mathrm{~cm}$, and $46.6 \mathrm{~kg}$ for $170 \mathrm{~cm}$. Incidentally, sixty-nine percent of the subjects considered the boundary values reasonable or less than expected. It seemed that many young women knew the limits for weight reduction, although they intended to become slender.

In conclusion, young Japanese, as well as western, women have a tendency to believe that they are fat even if they are classified into the thin or normal category. They have been getting thinner over the past 25 years or more and are continuing to do so. The boundary weight of excessive leanness for each height was statistically calculated from an allometric equation and found to be consistent with the sense of the subjects. It is desirable that young women do not wish to lose weight below the limits of the boundary weight proposed in this study. As is generally known, excessive weight 
reduction affects the human body especially young women of reproductive age. Diet often employed in the way of weight reduction has a risk for the development of rich and healthy eating habits. While there is a trend that leanness is ideal for preventing us from life-style-induced diseases, we should note that body fat is also beneficial to store energy, retain heat under cold conditions, and protect the organs of the body.

Since self-reported height and weight were employed in this study, their reliability should be tested elsewhere. There are some investigations on the differences between self-reported and directly measured height and weight. Mable et al. (1988) described that the report in the body image questionnaire was highly reliable for the college students, while Nishizawa et al. (2002) found that self-reported values slightly underestimated the actual weight in the junior and senior high school students. Meanwhile, the boundary weights proposed here are easily changeable in connection with the calculation, which depends on percentages of essential fat. It is unclear to what extent the information about minimum weight leads young women to stop excessive weight loss. There is room for further investigation on these points.

Acknowledgments The authors wish to thank the college staff responsible for collecting replies to the questionnaires. This work was supported in part by a grant from the Urakami Foundation.

\section{References}

Aoyama S (1978) Physique idealized by female university students. Jpn J School Health 20: 196-200 (in Japanese)

Brozek J, Grande F, Anderson JT and Keys A (1963) Densitometric analysis of body composition: revision of some quantitative assumptions. Ann NY Acad Sci 110: 113140

Caradas AA, Lambert EV, Charlton KE (2001) An ethnic comparison of eating attitudes and associated body image concerns in adolescent South African schoolgirls. J Hum Nutr Dietet 14: 111-120

Cohn LD, Adler NE, Irwin CE, Millstein SG, Kegeles SM, Stone G (1987) Body-figure preferences in male and female adolescents. J Abnorm Psychol 96: 276-279

Fallon AE, Rozin P (1985) Sex differences in perceptions of desirable body shape. J Abnorm Psychol 94: 102-105

Fox EL (1979) Sports Physiology. Holt-Saunders Japan, Tokyo, 294

Fukunaga S, Kobayashi E (1993) The recognition of body weight in female students. Jpn J School Health 35: 396-404 (in Japanese with English abstract)

Imai K, Masuda T, Komiya S (1994) Actual state of misconception regarding physique and desire for slenderness in female adolescents. Jpn J Nutr 52: 75-82 (in Japanese with English abstract)

Japanese Society of Obesity (2000) A new judgment and diagnostic criteria for obesity. 6: 18-28 (in Japanese)
Kojima K, Shido K, Fujii J, Kondo K (1994) The association between body mass index and self-assessed symptoms among young women. Jpn J Public Health 41: 126-130 (in Japanese with English abstract)

Lake AJ, Staiger PK, Glowinski H (2000) Effect of western culture on women's attitudes to eating and perceptions of body shape. Int J Eat Disord 27: 83-89

Lee S (1993) How abnormal is the desire for slimness? A survey of eating attitudes and behaviour among Chinese undergraduates in Hong Kong. Psychol Med 23: 437-451

Lohman TG (1981) Skinfolds and body density and their relation to body fatness. A review. Human Biol 53: 181-225

Mable HM, Balance WDG, Galgan RJ (1988) Reliability and accuracy of self-report of a new body-image measure. Perceptual and Motor Skills 66: 861-862

Malina RM, Bouchard C (1991) Growth, Maturation, and Physical Activity. Human Kinetics, Champaign, 50-51

Matsuura K, Fujimura M, Nozawa Y, Iida Y, Hirayama M (1992) The body shape preferences of Japanese female students. Int J Obesity 16: 87-93

Mizuno T, Hirata H, Aoyama S, Shi C, Ishikawa N (1968) An international comparative study on body concepts of youths. Res J Physical Education 12: 141-146

Ministry of Education (1983) Report of School Health Statistics in 1982. Ministry of Finance, Tokyo, 122 (in Japanese)

Ministry of Education (1999) Report of School Health Statistics in 1998. Ministry of Finance, Tokyo, 116 (in Japanese)

Ministry of Education (2000) Report of Physical Fitness and Performance Survey in 1999. Department of Physical Education, Tokyo, 248-255 (in Japanese)

Ministry of Health and Welfare (1986) Tables and Figures for Judging Obesity and Leanness. Daiichi-shuppan, Tokyo, 8-9 (in Japanese)

Nagamine S (1975) Evaluation of body fatness by skinfold measurements. JIBP Synth 4: 16-20

Nishizawa Y, Kida K, Noda M, Saito K, Sakano S, Asahi S, Mita R (2002) Comparison between self-reported and measurement values of height and weight: in the case of junior high and high school students. Jpn J School Health 44: 426-433 (in Japanese with English abstract)

Ritchie J (1988) Eating attitudes and behaviors of a sample of university students. NZ Med J 101: 238-240

Roche AF, Heymsfield SB, Lohman TG (1996) Human Body Composition. Human Kinetics, Champaign, 350

Tiggemann M, Pickering AS (1996) Role of television in adolescent women's body dissatisfaction and drive for thinness. Int J Eating Disorders 20: 199-203

Received: November 13, 2002

Accepted: January 27, 2003

Correspondence to: Yuji Takasaki, Department of Sport and Health Education, Akita University, 1-1 Tegatagakuen-machi, Akita 010-8502, Japan

e-mail: takasaki@ipc.akita-u.ac.jp 